\section{Essential role for Notch signaling in restricting developmental plasticity}

\author{
Nareg J.-V. Djabrayan, Nathaniel R. Dudley, \\ Erica M. Sommermann, and Joel H. Rothman ${ }^{1}$ \\ Department of Molecular, Cellular, and Developmental Biology, \\ Neuroscience Research Institute, University of California \\ at Santa Barbara, Santa Barbara, California 93106, USA
}

We report that Notch signaling is essential for the switch from developmental plasticity to commitment during Caenorhabditis elegans embryogenesis. The GLP-1 and LIN-12 Notch receptors act to set a memory state that affects commitment of cells arising from the major ectodermal progenitor (AB blastomere) several cell divisions later, thereby preventing their forced reprogramming by an endoderm-determining transcription factor. In contrast to Notch-dependent cell fate induction, this activity is autonomous to the $\mathrm{AB}$ lineage, is independent of the known cell fate-inducing Notch ligands, and requires a putative secreted Notch ligand, Delta Serrate Lag-3 (DSL-3). Thus, Notch signaling promotes developmental commitment by a mechanism that is distinct from that involved in specifying cell fates.

Supplemental material is available for this article.

Received June 27, 2012; revised version accepted September $21,2012$.

Fundamental to our understanding of developmental and stem cell biology is how cells switch from a pluripotent to a developmentally committed state. Methods for growing and engineering tissues and organs in vitro depend critically on the ability to manipulate this process. All somatic cells in early Caenorhabditis elegans embryos have been shown to be pluripotent, as evidenced by their capacity to be reprogrammed into cells of all three germ layers in response to forced expression of cell fate-regulating transcription factors (Horner et al. 1998; Zhu et al. 1998; Gilleard and McGhee 2001; Fukushige and Krause 2005). Later in embryogenesis, at about the time that the endoderm progenitor, or E cell, has progressed beyond three rounds of division (the 8E stage) (Joshi et al. 2010), cells become refractory to reprogramming by these factors, marking a major transition from plasticity to restriction in developmental potential (e.g., as can be observed by challenging normally nonendodermal precursor cells to undergo endoderm development) (Supplemental Fig. S1A). While cell-autonomous mechanisms in this critical developmental transition (e.g., Joshi et al. 2010) are known, the action of cell-extrinsic signaling in this process has not been well characterized.

[Keywords: Notch; reprogramming; embryo culture; commitment; plasticity] ${ }^{1}$ Corresponding author

E-mail rothman@lifesci.ucsb.edu

Article is online at http://www.genesdev.org/cgi/doi/10.1101/gad.199588.112.
The contact-dependent signal transduction mechanism known as Notch signaling is broadly deployed to direct cell identity throughout metazoan development (ArtavanisTsakonas and Muskavitch 2010). In C. elegans, Notch signaling is known primarily from its role in specifying cell identities and regulating cell behavior in the embryo, larvae, and adult germline (Kodoyianni et al. 1992; Berry et al. 1997; Chen and Greenwald 2004; Shaye and Greenwald 2005; McGovern et al. 2009). Here we show that Notch pathway components are essential for a completely distinct function independent of their action in specifying cellular differentiation: regulating the ability of embryonic cells to be reprogrammed. We show that the Notch receptor GLP-1 restricts the lineage of $A B$, the major embryonic ectoblast, from being reprogrammed into endoderm by a mechanism that is autonomous to the $\mathrm{AB}$ lineage and therefore distinct from the known early embryonic inductions. Furthermore, we implicate a presumptive Notch ligand, Delta Serrate Lag-3 (DSL-3), in the process that prevents cells in the $A B$ lineage from becoming reprogrammed but not in specifying cell identity in this lineage per se. These findings reveal that Notch controls the transition from plasticity to committed differentiation independent of its previously known action in cell fate specification.

\section{Results and Discussion}

Contact-dependent signaling through Notch-type receptors is recursively and widely deployed to specify the identity of many descendants of $\mathrm{AB}$, the anterior blastomere of the two-cell C. elegans embryo, which generates most of the ectoderm (Priess et al. 1987; Moskowitz and Rothman 1996; Schnabel and Priess 1997; Priess 2005). As Notch signaling functions most prominently prior to the plasticity $\rightarrow$ commitment transition, we wondered whether it might also act in restricting developmental plasticity. Indeed, we found that eliminating the function of the GLP-1 Notch receptor greatly extends the period during which nonendodermal cells can be reprogrammed into endoderm in response to the endoderm-promoting END-3 GATA transcription factor (Fig. 1A). In the absence of GLP-1 function, lineage reprogramming, evident by expression of several endodermal markers, can occur as late as the $20 \mathrm{E}$ stage, well after developmental plasticity is normally lost in wild-type embryos (Fig. 1B,C; Supplemental Fig. S3). This period of extended plasticity does not continue indefinitely, however, as cells do not respond to ectopic END-3 when its expression is induced late in morphogenesis (i.e., at approximately the "twofold

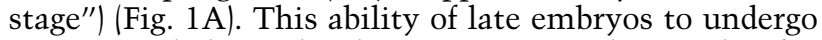
ectopic endoderm development is not the result of a general defect in differentiation, as $g l p-1(-)$ embryos undergo timely development and differentiation (Hutter and Schnabel 1994; Moskowitz et al. 1994; Schnabel and Priess 1997; data not shown), albeit with altered cell lineage patterns and fates, owing to misspecification of cells within the AB lineage. GLP-1 appears to act at least in part through canonical Notch signaling in this process: We found that the LAG-1 transcription factor, which transduces Notch inductive signals /Christensen et al. 1996), is also required for the temporal restriction in developmental plasticity (Table 1). 

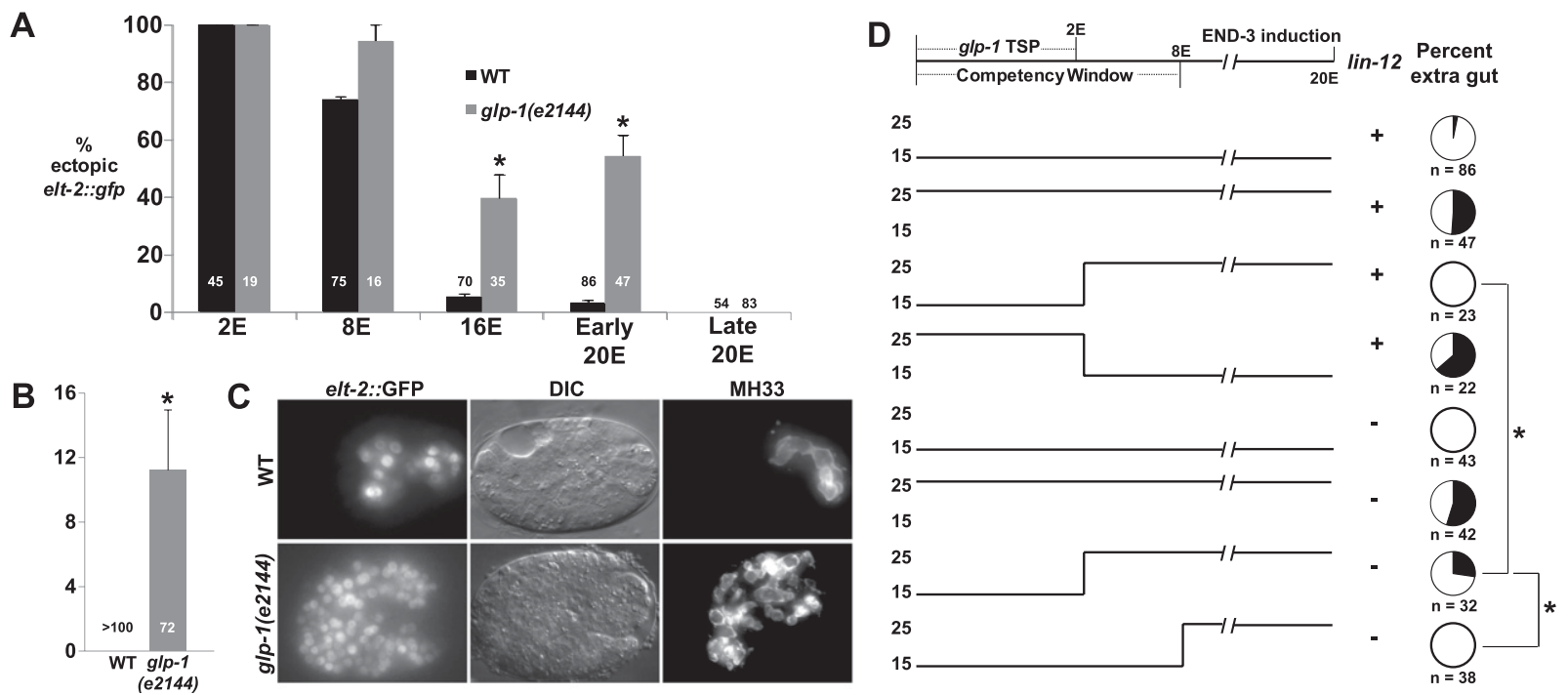

Figure 1. Extended period of developmental plasticity in embryos lacking GLP-1/Notch function, and temporal requirement for GLP-1. (A) Proportion of terminal embryos with ectopic elt-2::GFP in wild-type (WT) and glp-1(e2144) embryos following induction of END-3 at the indicated stage. "Early 20E" indicates that END-3 was induced in embryos shortly after the last E descendants were born (approximately "bean" to "comma" stage). "Late 20E" indicates that END-3 was induced at approximately the "twofold" stage of morphogenesis, based on time from the two- to four-cell stage. Numbers in bars indicate total embryos carrying the hs-end-3 array scored. (B) Proportion of terminal embryos with ectopic expression of the late gut differentiation marker IFB-2, detected with antibody MH33 (Zhu et al. 1998) following induction of END-3 at the 20E stage. $(C)$ Expression of intestinal differentiation markers following late activation of END-3 in embryos of the indicated genotype. $(D)$ Timelines of temperature shift experiments. Embryos were held at the indicated temperature [permissive $\left(15^{\circ} \mathrm{C}\right)$ or nonpermissive $\left(25^{\circ} \mathrm{C}\right)$ for the glp-1(e2144) mutation] and shifted at the indicated developmental stage. (Top) The known temperature-sensitive period for GLP-1 lethality (Priess et al. 1987) and the normal period of developmental plasticity ("competency window") are shown on the developmental time line. lin12(-) indicates that the gene was knocked down by RNAi in the mothers of the embryos where indicated. Pie diagrams show the proportion of embryos with ectopic endoderm; the total number of embryos carrying the END-3 transgene is indicated below each. In $B-D$, hs-end-3 was activated at a stage equivalent to the $20 \mathrm{E}$ stage in wild-type embryos. Error bars represent standard error. $\left(^{\star}\right)$ Fisher's exact test, $P<0.01$.

We found that when GLP-1 is inactivated prior to the 28-cell (2E) stage, embryos remain competent to respond to late (up to the 20E stage) ectopic expression of END-3 (Fig. 1A,D); reactivating GLP-1 function after the 28-cell stage does not reverse this effect (Fig. 1D). In contrast, when GLP-1 is inactivated only after the 28-cell stage, embryos become developmentally committed at the normal time (approximately 8E stage) (Fig. 1D). These results suggest that GLP-1/Notch sets up a memory state in the early embryo that activates the plasticity $\rightarrow$ commitment transition later in embryogenesis.

After the early inductive interactions in the AB lineage, mediated by maternal GLP-1, zygotically expressed GLP1 and its paralog, LIN-12, act redundantly to induce the fates of a small subset of AB-derived cells (Hutter and Schnabel 1994; Moskowitz and Rothman 1996; Henderson et al. 1997). Thus, LIN-12 might compensate for the absence of GLP-1 in regulating developmental plasticity after the 28-cell stage. We found that while embryos lacking only LIN-12 function become developmentally committed at the same time (approximately 8E stage) as in wild type, embryos lacking both GLP-1 and LIN-12 after the 28-cell stage can be provoked to produce ectopic endoderm late in development (Fig. 1D). Consistent with the known requirement of early GLP-1 activity for LIN-12 expression (Moskowitz and Rothman 1996), we observed no significant difference in the ability of embryos to be developmentally reprogrammed when GLP-1 activity was absent throughout embryogenesis in lin-12(RNAi) embryos compared with lin-12(+), embryos (Fig. 1D). It is possible that Notch signaling is necessary only to the $8 \mathrm{E}$ stage to restrict plasticity. Indeed, we found that lin-12(-) embryos in which GLP-1 activity was maintained until the $8 \mathrm{E}$ stage and then subsequently inactivated were resistant to END-3-mediated reprogramming (Fig. 1D). These results define an apparently continuous requirement for Notch function in the transition from a plastic to a committed state, including an essential early $(<28$-cell) requirement mediated by GLP-1 alone and a later (>28-cell) requirement in which either GLP-1 or LIN-12 appears to be sufficient.

As with the known early Notch-mediated embryonic inductions, we found that GLP-1/Notch function in restricting developmental plasticity is limited to $A B$ descendants. While partial wild-type embryos derived by laser ablation of either $A B$ or its sister, $P_{1}$, showed the

Table 1. Test of Notch signaling components in the restriction of developmental plasticity

\begin{tabular}{lc}
\hline RNAi & Embryos with ectopic elt-2::gfp \\
\hline L4440 & $1.44 \% \pm 1.35 \%(n=140)$ \\
lin-12 & $0 \%(n=43)$ \\
lag-2 & $1.54 \% \pm 1.39 \%(n=65)$ \\
apx-1 & $0 \%(n=40)$ \\
lag-1 & $25.8 \% \pm 5.6 \%(n=62)^{\mathrm{a}}$ \\
ref-1 & $0 \%(n=32)$ \\
\hline
\end{tabular}

Percent of embryos showing widespread elt-2::GFP expression after END-3 induction at the 20E stage is reported. L4440 is the control feeder strain.

${ }^{\text {a}}$ Fisher's exact test, $P<0.01$, compared with control L4440 strain. 
same temporal restriction to developmental reprogramming as in intact embryos (Supplemental Fig. S4A,C), ABderived partial embryos lacking GLP-1 could be provoked to develop endoderm well after the period in which developmental plasticity is normally lost (Fig. 2B,D). In contrast, this temporal extension of plasticity was not seen in $\mathrm{P}_{1}$-derived $g 1 p$-1(-) partial embryos (Supplemental Fig. S4B), demonstrating the $\mathrm{AB}$ specificity.

Given these observations and the known role of $\mathrm{P}_{1}$ descendants as the source of early inductive Notch signals that pattern the $\mathrm{AB}$ lineage (summarized in Fig. 2A; Priess et al. 1987; Schnabel and Priess 1997; Priess 2005), it was reasonable to suppose that the signals required to restrict developmental plasticity in $\mathrm{AB}$ descendants later in development might also arise from $\mathrm{P}_{1}$
A

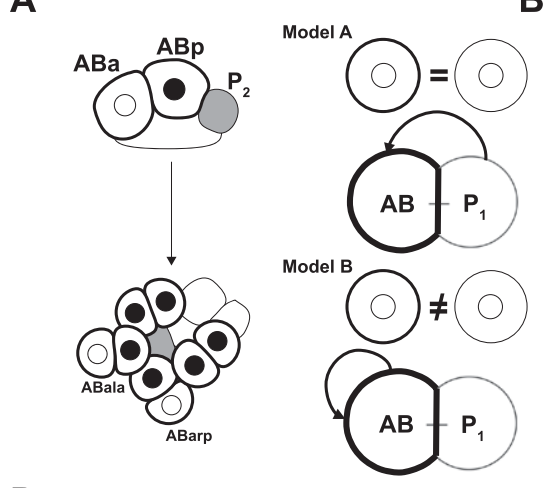

D

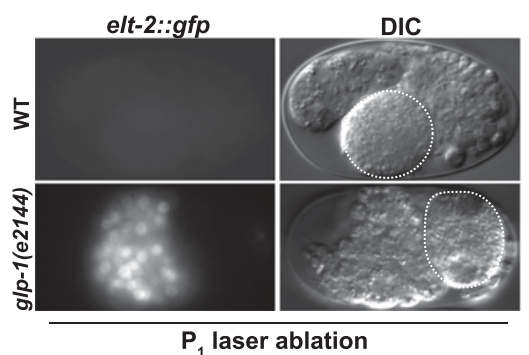

B

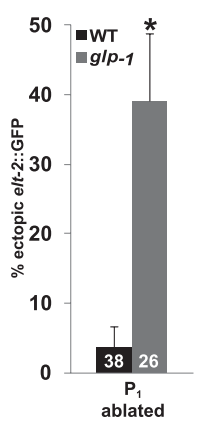

E elt-2::gfp

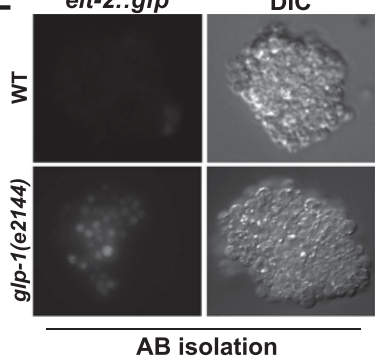

Figure 2. Notch signals regulating developmental plasticity are specific to the $\mathrm{AB}$ lineage. (A, left panel). Summary of early known cell fate-inducing Notch signals activated by $\mathrm{P}_{1}$ descendants. Gray-filled cells, derived from $\mathrm{P}_{1}$, signal their AB-derived Notch-expressing neighbors. Black outlines indicate cells expressing the GLP-1/Notch receptor. Cells in which Notch signal transduction has been received by signaling from $\mathrm{P}_{1}$ descendants contain black nuclei. (Right panel) Alternative models for Notch-dependent regulation of developmental plasticity. Circles at the top of each model represent isolated AB cells with (heavy lines) or without (light lines) GLP-1 present. Model A: Inductive signals from $\mathrm{P}_{1}$ descendants both activate cell fates and restrict developmental plasticity. Model B: AB-derived signals, distinct from the cell fate-inducing signals arising from $P_{1}$ descendants, restrict developmental plasticity. (B) Proportion of $\mathrm{P}_{1}$-ablated embryos from wild-type and $g l p-1(e 2144)$ embryos that express ectopic elt-2:: GFP following late induction of END-3 expression. (C) Proportion of partial embryos obtained from in vitro culturing of physically isolated $\mathrm{AB}$ blastomeres from wild-type and $g l p-1(e 2144)$ embryos that express ectopic elt-2::GFP. (D) elt-2:: GFP expression in wild-type and $g l p-1(e 2144)$ embryos in which $\mathrm{AB}$ was isolated by laser ablation followed by late induction of END-3 expression. Ablated blastomeres are denoted by dashed lines. (E) elt-2::GFP in partial embryos obtained from physically isolated AB blastomeres. In all experiments, END-3 was induced by heat shock when the number of cells corresponded approximately to the $20 \mathrm{E}$ stage in intact wild-type embryos. In $B$ and $C$, numbers in the bars represent the total number of embryos carrying the END-3 transgene. $\left(^{\star}\right)$ Fisher's exact test, $\left.P=0.01 ;{ }^{\star \star}\right)$ Fisher's exact test, $P<0.01$. Error bars represent standard error. descendants (Model A, Fig. 2A). However, several observations indicated that this is not the case. First, although the entire $\mathrm{AB}$ lineage appears to be resistant to detype embryos, two of the $\mathrm{AB}$ great-granddaughters, while expressing the GLP-1/Notch receptor, never receive Notch gnals and would therefore be expected to show extended evelopmental plasticity (Hutter and Schnabel 1994; the Notch ligand that induces the fate of half of the AB(Mango et al. 1994; Mello et al. 1994), is not equired to restrict developmental plasticity (Table 1). Furthermore, cell ablations (Fig. 2B,D; Supplemental Fig. $4 \mathrm{~A}$ ) indicated that a viable $\mathrm{P}_{1}$ cell is not required for commitment of $\mathrm{AB}$ descendants to a nonendodermal fate. However, this experiment does not eliminate the caveat that $\mathrm{P}_{1}$-derived signals might be produced by the ablated cell (e.g., Goldstein 1992). To eliminate all potential $\mathrm{P}_{1}$-derived Notch signal, we physically isolated and cultured $\mathrm{AB}$ blastomeres (Edgar and Goldstein 2012) and tested for GLP-1-dependent restriction of developmental plasticity. This manipulation is known to prevent all Notch signaling to the AB lineage (Gendreau et al. 1994; Moskowitz et al. 1994). The resultant partial embryos differentiated (Supplemental Fig. $\mathrm{S} 5 \mathrm{~A}, \mathrm{~B})$ and produced endoderm when induced to express END-3 at early stages (Supplemental Fig. S5C,D). However, although they do not experience Notch signal from $\mathrm{P}_{1}$ descendants, the GLP-1-dependent block to reprogramming nonetheless persisted in such AB-derived embryos. Specifically, endoderm differentiation, as evident by elt-2::GFP expression as well as the presence of birefringent gut granules, an endogenous marker of endoderm differentiation (Babu 1974), could be activated in late $g l p-1(-)$ but not $g l p-1(+)$ AB-derived partial embryos (Fig. 2C,E; data not shown). Thus, posterior-derived Notch signals are not necessary for developmental commitment; rather, the plasticityregulating signals apparently arise from within the $A B$ lineage (Model B, Fig. 2A). These intra-AB signals cannot be attributed to the few known (and very limited) intra-AB inductions received by LIN-12, as LIN-12 is not expressed in embryos lacking $\mathrm{P}_{1}$-derived Notch signals (Moskowitz and Rothman 1996).

The only Notch ligand known to be expressed and function in the embryonic AB lineage is LAG-2, which activates zygotic expression of 1 in-12 and glp-1 (Moskowitz and Rothman 1996). However, we found that lag-2 knockdown did not affect the ability of late embryos to be reprogrammed (Table 1), suggesting the requirement for an unidentified AB-specific Notch ligand. The C. elegans genome encodes several other DSL-like Notch ligands (Chen and Greenwald 2004). We found that knocking down either of two DSL-encoding genes, $d s 1-1$ or $d s 1-3$, extended the period of developmental plasticity (Fig. 3A,B). Of these, only ds1-3 showed a requirement for commitment in the $\mathrm{AB}$ lineage specifically when partial embryos, obtained by laser ablation of $\mathrm{AB}$ or $\mathrm{P}_{1}$, were analyzed (Fig. 3C,D). Thus, like GLP-1/ Notch, DSL-3, which is predicted to be a secreted 
A

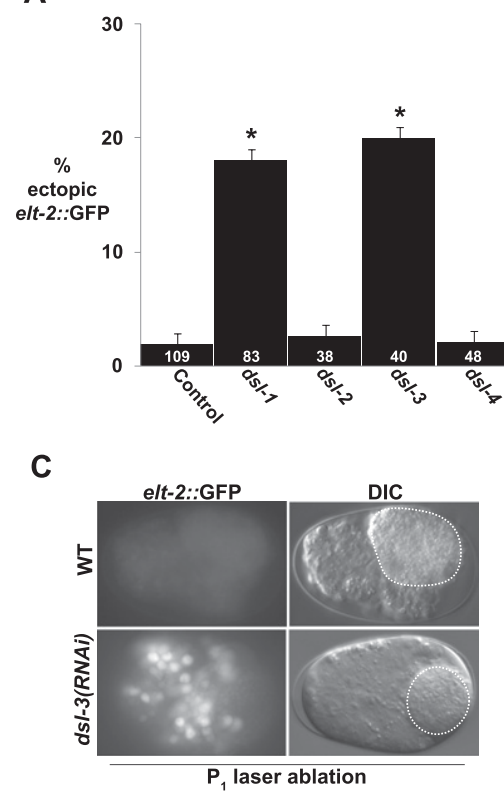

B

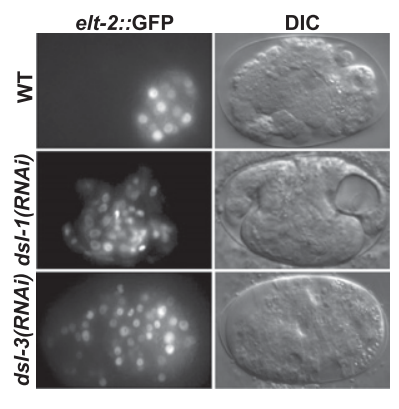

Previous work identified a role for a member of the C. elegans polycomb repressor complex, MES-2, in restricting developmental plasticity (Yuzyuk et al. 2009). In that study, it was shown that removal of mes-2 function enhances developmental plasticity at the $8 \mathrm{E}$ stage. It is therefore possible that MES-2 acts downstream from Notch signaling to promote commitment to differentiation. We found that RNAi knockdown of mes-2 in $g 1 p-1(-)$ embryos did not significantly $(P=1)$ increase the fraction of embryos $(53.9 \% \pm 9.8 \% ; n=26)$ that were reprogrammed, consistent with the possibility that Notch signaling and MES-2 function in the same pathway to restrict developmental plasticity. However, the findings that MES-2 function is not lineage-specific (Yuzyuk et al. 2009) and that inactivation of GLP-1 causes cells to remain plastic longer than those in embryos lacking MES-2 function suggest that MES-2 may act in a global pathway with multiple inputs, while Notch apparently acts in an AB-specific pathway that may impinge on MES-2 and other regulators of chromatin function.

In other systems, Notch signaling acts to

Figure 3. $d s l-3$ is required for commitment to differentiation in the $\mathrm{AB}$ lineage. (A) Proportion of embryos subjected to RNAi of the indicated gene that showed ectopic elt-2::GFP expression. (B) Endogenous and ectopic elt-2::GFP in terminal dsl-1(RNAi) and $d s l-3(R N A i)$ embryos. (C) elt-2::GFP in terminal $\mathrm{P}_{1}$-ablated wild-type and $d s l-3(R N A i)$ embryos. Ablated blastomeres are denoted by dashed lines. $(D)$ Proportion of isolated $\mathrm{P}_{1}$ or $\mathrm{AB}$ descendants of wild-type and dsl-3(RNAi) embryos expressing ectopic elt-2::GFP. In all experiments, END-3 was induced by heat shock when the number of cells corresponded approximately to the $20 \mathrm{E}$ stage in intact wild-type embryos. Numbers in bars are the total number of embryos carrying the END-3 transgene. $\left(^{\star}\right)$ Fisher's exact test, $P<0.01$. Error bars represent standard error.

protein (Chen and Greenwald 2004), apparently acts specifically on $\mathrm{AB}$ descendants to restrict developmental plasticity.

Consistent with its potential action on Notch signaling to the $\mathrm{AB}$ lineage, microarrays (Baugh et al. 2003) and expression patterns reported in the NEXTDB database (The Nematode Expression Pattern Database, http://nematode.lab.nig.ac.jp/ indicate that $d s 1-3$ expression overlaps temporally with that of the GLP-1 and LIN-12 Notch receptors. Moreover, we detected dsl-3 transcripts by in situ hybridization throughout the embryo as early as the two-cell stage, with stronger, more restricted staining primarily in AB-derived embryonic cells later in development (Supplemental Fig. S6). While knockdown of $d s l-3$ under conditions that eliminate a detectable message (Supplemental Fig. S6) impairs developmental commitment, we observed no overt phenotype of larvae arising from such embryos, consistent with other reports (Kamath et al. 2003; Sonnichsen et al. 2005). Thus, while $d s 1-3$ transcripts are present throughout the early embryo, DSL-3 may block reprogramming by acting specifically through Notch receptors expressed only in $\mathrm{AB}$ descendants. These findings suggest two fundamentally different modes of action for Notch signaling in development, with one set of ligands that controls specification of cell identity and another that mediates an auxiliary role in regulating developmental plasticity (Supplemental Fig. S7). coordinate proliferation and differentiation, as observed, for example, with mammalian Notch1, which is necessary for both the proliferation of neuronal stem cell populations and their differentiation into specific neuronal types (Hitoshi et al. 2002; Wang et al. 2009; Ables et al. 2010; Zhou et al. 2010; Matsumoto et al. 2011). We showed that in C. elegans, Notch can act not only as a factor in specifying cell types, but also, through an apparently distinct process, in the general restriction of developmental plasticity. The diversification of Notch function through the action of different ligands may point to a new role for Notch signaling in regulating the multipotential, stem cell-like properties of developing cells.

\section{Materials and methods}

Worm culture and strains

Unless otherwise noted, strains were reared at $20^{\circ} \mathrm{C}$ on NGM agar plates fed on OP50 Escherichia coli. glp-1(e2144) worms were reared at $15^{\circ} \mathrm{C}$, and all experiments with these mutants were performed at $25^{\circ} \mathrm{C}$, except where indicated. The following strains were constructed for this study: JR1753 unc-119(ed4) III; wEx690 [unc-119(+) hsp16-2/41::end-3(+)]; WIs84 [rol-6(su1006) elt-2::GFP] and JR3279 unc-119(ed4) glp-1(e2144ts) III; wEx690 [unc-119(+) hsp16-2/41::end-3(+)]; wIs84 [rol-6(su1006) elt-2:: GFP]. Strain JG7 cals6 [hsp16-2::elt-1(+)]; ijIs12 [dpy7::GFP rol-6(su1006)] was obtained from John Gilleard.

\section{RNAi}

E. coli RNAi feeding strains for glp-1, lin-12, lag-2, dsl-1, dsl-4, lag-1, and ref-1 were obtained from the Ahringer RNAi library (Fraser et al. 2000; Kamath et al. 2003). The $d s 1-2, d s l-3, d s 1-5, d s 1-7$, and $a p x-1$ genes were cloned into plasmid L4440 using appropriate primers carrying added restriction sites to facilitate cloning (sequences furnished on request) and were transformed into HT115 for RNAi feeding. In the case of $g l p-1$, apx-1, and lag-1, which show lethal RNAi phenotypes, the efficacy of 
RNAi was determined by scoring for embryonic lethality. L3 worms were fed on RNAi feeding bacteria for $3 \mathrm{~d}$ at $15^{\circ} \mathrm{C}$. Embryos were dissected from gravid adults on the third day and used in heat-shock experiments.

\section{Analysis of responsiveness to cell fate reprogramming}

Embryos from strain JR1753 or the indicated mutant or knockdown strains were isolated at the two-cell stage, and END-3 expression was induced via heat shock after they had been allowed to develop to various stages of $\mathrm{E}$ development. Embryos were returned to $20^{\circ} \mathrm{C}$, allowed to develop overnight, and scored for expression of elt-2::GFP. We found that induction of END-3 at any stage leads to ectopic expression of elt-2::GFP in a low number of small nuclei; however, this expression did not appear to reflect bona fide reprogramming, as ectopic expression of other markers of gut differentiation was not observed in such cells. We scored only embryos with widespread elt-2::GFP expression as positive in all experiments (e.g., Supplemental Fig. S2). For analysis of differentiation markers, terminal embryos were prepared for immunofluorescence. In all heatshock experiments, embryos were shifted for $30 \mathrm{~min}$ to $33^{\circ} \mathrm{C}$, with the exception that embryos from the laser ablation and in vitro culture experiments were heat-shocked for $15 \mathrm{~min}$ at $33^{\circ} \mathrm{C}$.

\section{Temperature shift experiments}

To block GLP-1 function continuously, glp-1(e2144) embryos were isolated at the two- to four-cell stage and incubated immediately at the nonpermissive temperature $\left(25^{\circ} \mathrm{C}\right)$ through to the $20 \mathrm{E}$ stage, at which point they were heat-shocked. To block GLP-1 function later, glp-1(e2144) embryos were isolated at the permissive temperature $\left(15^{\circ} \mathrm{C}\right)$ in a $15^{\circ} \mathrm{C}$ temperature-controlled room. Following incubation at $15^{\circ} \mathrm{C}$ past the 28-cell stage or $8 \mathrm{E}$ stage, embryos were shifted to the nonpermissive temperature and incubated until the $20 \mathrm{E}$ stage, at which point they were heat-shocked. Shift-down assays were performed by isolating and incubating glp-1(e2144) embryos at the nonpermissive temperature from the two- to four-cell stages and shifting to the permissive temperature after the 28-cell stage. After allowing them to develop to the 20E cell stage, embryos were heat-shocked.

\section{Laser ablation}

$\mathrm{AB}$ or $\mathrm{P}_{1}$ blastomeres were ablated at the two-cell stage with a pulsed laser microbeam (Photonic Instruments, Inc.) as described in Bowerman et al. (1992). After ablation, embryos from either wild-type or glp-1(e2144) worms were incubated to the equivalent of the $20 \mathrm{E}$ stage at $25^{\circ} \mathrm{C}$, based on observation of total cell number. Embryos were then heat-shocked for $15 \mathrm{~min}$ at $33^{\circ} \mathrm{C}$ and incubated overnight at $20^{\circ} \mathrm{C}$ before scoring.

\section{In vitro culture}

The methods for culturing isolated blastomeres were adapted from Edgar and Goldstein (2012). After enzymatic digestion of the eggshell, blastomeres were separated by forcing embryos through a pulled glass needle. $\mathrm{AB}$ or $\mathrm{P}_{1}$ blastomeres were identified by size and mounted in $14 \mu \mathrm{L}$ of Edgar's growth medium on a glass slide under a coverslip mounted with clay feet. Slides were sealed with Vaseline to prevent desiccation. To assess the ability of cells grown in isolation to differentiate, $\mathrm{AB}$ blastomeres from strain JG7 were incubated overnight at $20^{\circ} \mathrm{C}$ and scored for expression of the epidermal marker $d p y-7::$ GFP (Gilleard and McGhee 2001). $P_{1}$ blastomeres from strain JR3339 were grown overnight at $20^{\circ} \mathrm{C}$ and scored for expression of muscle marker unc-54::GFP. To test whether cultured $\mathrm{AB}$ blastomeres exhibit the same transition from developmental plasticity to commitment as intact embryos, $\mathrm{AB}$ isolates from wild-type embryos were allowed to develop at $20^{\circ} \mathrm{C}$ to the equivalent of the $2 \mathrm{E}$ and $20 \mathrm{E}$ stage, as determined by cell number; heat-shocked for $15 \mathrm{~min}$ at $33^{\circ} \mathrm{C}$; returned to $20^{\circ} \mathrm{C}$; and scored for elt-2::GFP expression after overnight incubation. To test for GLP-1 dependence in commitment to differentiation, $\mathrm{AB}$ blastomeres were isolated from wild-type and glp-1(e2144) embryos, grown in vitro at $25^{\circ} \mathrm{C}$ to the equivalent of the $20 \mathrm{E}$ stage, and heat-shocked for $15 \mathrm{~min}$ at $33^{\circ} \mathrm{C}$. After overnight incubation at $20^{\circ} \mathrm{C}$, descendants were scored for elt-2::gfp expression.

\section{In situ hybridization}

Mixed-stage embryos from N2, ds1-1(ok810), ds1-3(RNAi), or glp-1(e2144) worms were stained with DIG-labeled RNA probes for $d s l-1$ and $d s l-3$. Probes were made as described (http://www.faculty.ucr.edu/mmaduro) with appropriate primers (sequences provided on request). BLASTN analysis of the genomic sequences amplified by these primers indicated that only the targeted gene would be predicted to hybridize significantly.

Embryos obtained from bleached gravid adults were forced through 27.5-gauge needles to break up adult corpses and then washed three times in M9. Embryos in M9 suspension were immediately dispensed in $10-\mu \mathrm{L}$ aliquots onto $14 \times 14-\mathrm{mm}$ square wells of polylysine-coated slides, covered with coverslips, and frozen. After freeze-crack, the Kohara Laboratory protocol for "large-scale fixation of embryos" was followed (http://nematode. lab.nig.ac.jp/method/protocol.php?docbase=insitu_embryo), replacing the dehydration (C.II.11-C.II.1112) and proteinase K treatment steps (D.I.1-D.I.19) with two 5-min washes in PBT. Hybridizations and subsequent warm temperature washes were performed at $58^{\circ} \mathrm{C}$. For probe detection, slides were immersed in $400 \mu \mathrm{L}$ of premixed NBT+BCIP solution (Roche Diagnostics $\mathrm{GmbH}$, reference 11-681-451-001) mixed with $40 \mathrm{~mL}$ of staining buffer and developed overnight at room temperature.

\section{Imaging and immunofluorescence analysis}

The embryonic stage in any given experiment was determined by observing the number of elt-2::gfp-expressing cells with an Olympus SZX12 fluorescence dissecting microscope. Terminal embryos were scored for ectopic elt-2::gfp expression on either a Zeiss Axioskop 2 or Nikon Microphot SA fluorescence compound microscope. Embryos were mounted on 3\% agar pads in egg salts (Edgar and Goldstein 2012). Images were processed with NIH ImageJ. For immunofluorescence analyses, embryos were mounted and stained with antibodies MH33 and 1CB4, as described in Zhu et al. (1998).

\section{Acknowledgments}

We are grateful to M. Kourakis, B. Birsoy, L. Chen, P.M. Joshi, and J. Casanova for comments on the manuscript. Some nematode strains were provided by the Caenorhabditis Genetics Center, which is funded by the NIH National Center for Research Resources (NCRR). N.J.-V.D. was supported in part by a training grant from the California Institute of Regenerative Medicine. This work was supported by grants from the NIH (HD062922) and March of Dimes (FY2007-804) to J.H.R.

\section{References}

Ables JL, Decarolis NA, Johnson MA, Rivera PD, Gao Z, Cooper DC, Radtke F, Hsieh J, Eisch AJ. 2010. Notch1 is required for maintenance of the reservoir of adult hippocampal stem cells. I Neurosci 30: 10484-10492.

Artavanis-Tsakonas S, Muskavitch MA. 2010. Notch: The past, the present, and the future. Curr Top Dev Biol 92: 1-29.

Babu P. 1974. Biochemical genetics of Caenorhabditis elegans. Mol Genet Genomics 135: 39-44.

Baugh LR, Hill AA, Slonim DK, Brown EL, Hunter CP. 2003. Composition and dynamics of the Caenorhabditis elegans early embryonic transcriptome. Development 130: 889-900.

Berry LW, Westlund B, Schedl T. 1997. Germ-line tumor formation caused by activation of glp-1, a Caenorhabditis elegans member of the Notch family of receptors. Development 124: 925-936.

Bowerman B, Tax FE, Thomas JH, Priess JR. 1992. Cell interactions involved in development of the bilaterally symmetrical intestinal valve cells during embryogenesis in Caenorhabditis elegans. Development 116: 1113-1122.

Chen N, Greenwald I. 2004. The lateral signal for LIN-12/Notch in C. elegans vulval development comprises redundant secreted and transmembrane DSL proteins. Dev Cell 6: 183-192.

Christensen S, Kodoyianni V, Bosenberg M, Friedman L, Kimble J. 1996. lag-1, a gene required for lin-12 and glp-1 signaling in Caenorhabditis elegans, is homologous to human CBF1 and Drosophila $\mathrm{Su}(\mathrm{H})$. Development 122: 1373-1383.

Edgar LG, Goldstein B. 2012. Culture and manipulation of embryonic cells. Methods Cell Biol 107: 151-175. 
Fraser AG, Kamath RS, Zipperlen P, Martinez-Campos M, Sohrmann M, Ahringer J. 2000. Functional genomic analysis of C. elegans chromosome I by systematic RNA interference. Nature 408: 325-330.

Fukushige T, Krause M. 2005. The myogenic potency of HLH-1 reveals wide-spread developmental plasticity in early C. elegans embryos. Development 132: 1795-1805.

Gendreau SB, Moskowitz IP, Terns RM, Rothman JH. 1994. The potential to differentiate epidermis is unequally distributed in the $\mathrm{AB}$ lineage during early embryonic development in C. elegans. Dev Biol 166: 770-781.

Gilleard JS, McGhee JD. 2001. Activation of hypodermal differentiation in the Caenorhabditis elegans embryo by GATA transcription factors ELT-1 and ELT-3. Mol Cell Biol 21: 2533-2544.

Goldstein B. 1992. Induction of gut in Caenorhabditis elegans embryos. Nature 357: 255-257.

Henderson ST, Gao D, Christensen S, Kimble J. 1997. Functional domains of LAG-2, a putative signaling ligand for LIN-12 and GLP-1 receptors in Caenorhabditis elegans. Mol Biol Cell 8: 1751-1762.

Hitoshi S, Alexson T, Tropepe V, Donoviel D, Elia AJ, Nye JS, Conlon RA, Mak TW, Bernstein A, van der Kooy D. 2002. Notch pathway molecules are essential for the maintenance, but not the generation, of mammalian neural stem cells. Genes Dev 16: 846-858.

Horner MA, Quintin S, Domeier ME, Kimble J, Labouesse M, Mango SE. 1998. pha-4, an HNF-3 homolog, specifies pharyngeal organ identity in Caenorhabditis elegans. Genes Dev 12: 1947-1952.

Hutter H, Schnabel R. 1994. glp-1 and inductions establishing embryonic axes in C. elegans. Development 120: 2051-2064.

Joshi PM, Riddle MR, Djabrayan NJ, Rothman JH. 2010. Caenorhabditis elegans as a model for stem cell biology. Dev Dyn 239: 1539-1554.

Kamath RS, Fraser AG, Dong Y, Poulin G, Durbin R, Gotta M, Kanapin A, Le Bot N, Moreno S, Sohrmann M, et al. 2003. Systematic functional analysis of the Caenorhabditis elegans genome using RNAi. Nature 421: 231-237.

Kodoyianni V, Maine EM, Kimble J. 1992. Molecular basis of loss-offunction mutations in the glp-1 gene of Caenorhabditis elegans. Mol Biol Cell 3: 1199-1213.

Mango SE, Thorpe CJ, Martin PR, Chamberlain SH, Bowerman B. 1994. Two maternal genes, apx-1 and pie-1, are required to distinguish the fates of equivalent blastomeres in the early Caenorhabditis elegans embryo. Development 120: 2305-2315.

Matsumoto A, Onoyama I, Sunabori T, Kageyama R, Okano H, Nakayama KI. 2011. Fbxw7-dependent degradation of Notch is required for control of 'stemness' and neuronal-glial differentiation in neural stem cells. J Biol Chem 286: 13754-13764.

McGovern M, Voutev R, Maciejowski J, Corsi AK, Hubbard EJ. 2009. A 'latent niche' mechanism for tumor initiation. Proc Natl Acad Sci 106: $11617-11622$.

Mello CC, Draper BW, Priess JR. 1994. The maternal genes apx-1 and glp-1 and establishment of dorsal-ventral polarity in the early C. elegans embryo. Cell 77: 95-106.

Moskowitz IP, Rothman JH. 1996. lin-12 and glp-1 are required zygotically for early embryonic cellular interactions and are regulated by maternal GLP-1 signaling in Caenorhabditis elegans. Development 122: $4105-4117$.

Moskowitz IP, Gendreau SB, Rothman JH. 1994. Combinatorial specification of blastomere identity by glp-1-dependent cellular interactions in the nematode Caenorhabditis elegans. Development 120: 33253338.

Priess JR. 2005. Notch signaling in the C. elegans embryo. In WormBook (ed. The C. Elegans Community), WormBook . doi: 10.1895/wormbook. 1.4.1.

Priess JR, Schnabel H, Schnabel R. 1987. The glp-1 locus and cellular interactions in early C. elegans embryos. Cell 51: 601-611.

Schnabel R, Priess JR. 1997. Specification of cell fates in the early embryo. In C. elegans II, 2nd ed. (ed. DL Riddle et al.), pp. 361-382. Cold Spring Harbor Laboratory Press, Cold Spring Harbor, NY.

Shaye DD, Greenwald I. 2005. LIN-12/Notch trafficking and regulation of DSL ligand activity during vulval induction in Caenorhabditis elegans. Development 132: 5081-5092.

Sonnichsen B, Koski LB, Walsh A, Marschall P, Neumann B, Brehm M, Alleaume AM, Artelt J, Bettencourt P, Cassin E, et al. 2005. Fullgenome RNAi profiling of early embryogenesis in Caenorhabditis elegans. Nature 434: 462-469.
Wang Y, Tu W, Lou Y, Xie A, Lai X, Guo F, Deng Z. 2009. Mesenchymal stem cells regulate the proliferation and differentiation of neural stem cells through Notch signaling. Cell Biol Int 33: 1173-1179.

Yuzyuk T, Fakhouri TH, Kiefer J, Mango SE. 2009. The Polycomb complex protein mes-2/E $(z)$ promotes the transition from developmental plasticity to differentiation in C. elegans embryos. Dev Cell 16: 699-710.

Zhou ZD, Kumari U, Xiao ZC, Tan EK. 2010. Notch as a molecular switch in neural stem cells. IUBMB Life 62: 618-623.

Zhu J, Fukushige T, McGhee JD, Rothman JH. 1998. Reprogramming of early embryonic blastomeres into endodermal progenitors by a Caenorhabditis elegans GATA factor. Genes Dev 12: 3809-3814. 


\section{Erratum}

Genes \& Development 26: 2386-2391 (2012)

Essential role for Notch signaling in restricting developmental plasticity Nareg J.-V. Djabrayan, Nathaniel R. Dudley, Erica M. Sommermann, and Joel H. Rothman

In the above-mentioned article, the following citations and references were inadvertently excluded from the manuscript:

In situ hybridization was carried out based on methods described in Broitman-Maduro and Maduro (2011). Identification of the end-3 gene was first reported in Maduro et al. (2005).

Broitman-Maduro G, Maduro MF. 2011. In situ hybridization of embryos with antisense RNA probes. Methods Cell Biol 106: 253-270.

Maduro MF, Hill RJ, Heid PJ, Newman-Smith ED, Zhu J, Priess JR, Rothman JH. 2005. Genetic redundancy in endoderm specification within the genus Caenorhabditis. Dev Biol 284: 509-522. 


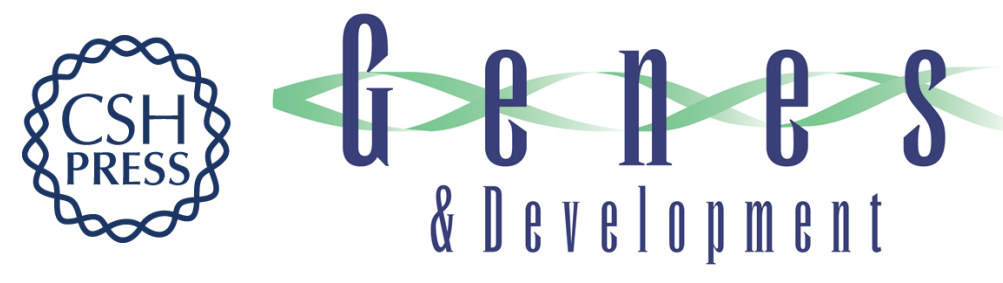

\section{Essential role for Notch signaling in restricting developmental plasticity}

Nareg J.-V. Djabrayan, Nathaniel R. Dudley, Erica M. Sommermann, et al.

Genes Dev. 2012, 26:

Access the most recent version at doi:10.1101/gad.199588.112

\section{Supplemental http://genesdev.cshlp.org/content/suppl/2012/10/25/26.21.2386.DC1 \\ Material}

Related Content Essential role for Notch signaling in restricting developmental plasticity Nareg J.-V. Djabrayan, Nathaniel R. Dudley, Erica M. Sommermann, et al. Genes Dev. March , 2013 27: 579

References This article cites 34 articles, 19 of which can be accessed free at: http://genesdev.cshlp.org/content/26/21/2386.full.html\#ref-list-1

Articles cited in:

http://genesdev.cshlp.org/content/26/21/2386.full.html\#related-urls

\section{License}

Email Alerting

Service

Receive free email alerts when new articles cite this article - sign up in the box at the top right corner of the article or click here.

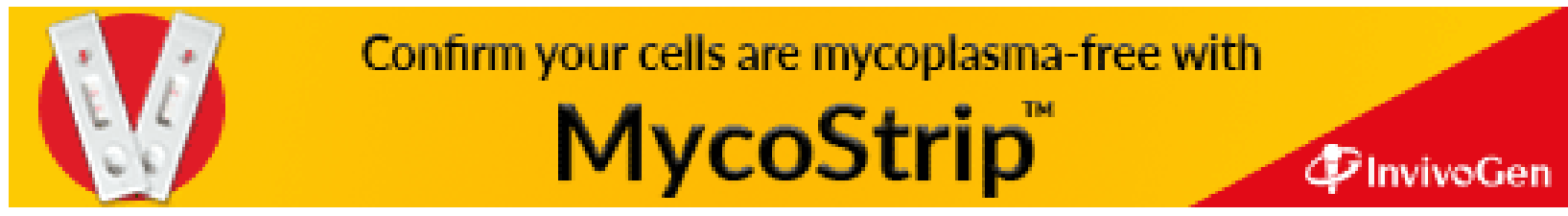

